\title{
Effects of intensive care unit ambient sounds on healthcare professionals: results of an online survey and noise exposure in an experimental setting
}

Nadine Schmidt ${ }^{1}$ Stephan M. Gerber ${ }^{1}$, Björn Zante ${ }^{2}$, Tom Gawliczek³ ${ }^{3}$ Alvin Chesham ${ }^{1}$ Klemens Gutbrod ${ }^{4}$, René M. Müri ${ }^{1,4}$, Tobias Nef ${ }^{1,5^{*}}$ (D) Joerg C. Schefold ${ }^{2 \dagger}$ and Marie-Madlen Jeitziner ${ }^{2+}$

\author{
*Correspondence: tobias.nef@ \\ artorg.unibe.ch \\ ${ }^{\dagger}$ Joerg C. Schefold and Marie- \\ Madlen Jeitziner contributed \\ equally to this work. \\ ${ }^{1}$ Gerontechnology \& Rehabilitation \\ Group, University of Bern, \\ Murtenstrasse 50, $\mathrm{CH}-3008$ Bern, \\ Switzerland \\ ${ }^{5}$ ARTORG Center for Biomedical \\ Engineering Research, University of \\ Bern, Murtenstrasse 50, $\mathrm{CH}-3008$ \\ Bern, Switzerland \\ Full list of author information is \\ available at the end of the article
}

\begin{abstract}
Background: Noise levels on intensive care units (ICUs) are typically elevated. While many studies reported negative effects of ICU ambient sounds on patients, only few investigated noise as a factor to influence well-being or performance in healthcare professionals.
\end{abstract}

Methods: An online survey in the German-speaking part of Switzerland was conducted to assess how ICU soundscapes are subjectively perceived by healthcare professionals. The questionnaire was answered by 348 participants. Additionally, effects of noise on working memory performance were evaluated in an experimental noise exposure setting. Twenty-six healthcare professionals and 27 healthy controls performed a 2-back object-location task while being exposed to either ICU or pink noise.

Results: Survey results demonstrate that a majority of participants was aware of heightened noise levels. Participants reported that mostly well-being, performance, and attention could be reduced, along with subjective annoyance and fatigue by ICU ambient sounds. Although no significant effects of noise exposure on working memory performance was observed, self-assessments revealed significantly higher stress levels, increased annoyance and distraction ratings as well as decreased confidence in performance after ICU-noise exposure.

Conclusion: Subjective assessments indicate that heightened noise levels on ICUs induce annoyance, with heightened stress levels, impaired well-being, and reduced performance being potential consequences. Empirical evidence with objective and physiological measures is warranted.

Keywords: Intensive care unit, Noise, Healthcare professionals, Working memory, Annoyance, Performance (c) The Author(s). 2020 Open Access This article is licensed under a Creative Commons Attribution 4.0 International License, which permits use, sharing, adaptation, distribution and reproduction in any medium or format, as long as you give appropriate credit to the original author(s) and the source, provide a link to the Creative Commons licence, and indicate if changes were made. The images or other third party material in this article are included in the article's Creative Commons licence, unless indicated otherwise in a credit line to the material. If material is not included in the article's Creative Commons licence and your intended use is not permitted by statutory regulation or exceeds the permitted use, you will need to obtain permission directly from the copyright holder. To view a copy of this licence, visit http://creativecommons.org/licenses/by/4.0/. 


\section{Background}

Noise is known to exert negative effects on human beings [1, 2]. Also in the hospital context, studies showed that sleep quality of patients might be impaired due to ambient sounds [3]. Therefore, the World Health Organization (WHO) recommended 20 years ago that sound pressure levels in intensive care units (ICUs) should not exceed $35 \mathrm{dBA}$ [1]. Since then, several studies demonstrated that this guideline can hardly be met [4-8]. Exceeding noise levels do not only seem to affect patients but also healthcare professionals: Studies showed that noise on ICUs contributes to annoyance, irritation, fatigue, stress, and occupational burnout symptoms of healthcare professionals (HCPs) [9-13]. Moreover, in one study noise was named to be a considerable performance obstacle [14]. Nonetheless, studies about effects of ICU noise on cognition and working performance are sparse. More studies addressed cognition and working performance in operating rooms (ORs): In a survey, a majority of participating surgical healthcare professionals reported that communication with colleagues and concentration is impaired by OR ambient sounds with errors being more likely [15]. In a study of Murthy et al. mean shortterm and working memory performance of 20 anesthesia residents was significantly lower when exposed to OR noise compared to when exposed to no ambient sounds [16]. Also, outside the hospital context, ambient noise was found to have detrimental effects for individuals $[17,18]$. These effects seem to be dependable on specific acoustical characteristics (e.g., loudness or frequency) and non-acoustical characteristics of the sound (e.g., content or meaning) [19, 20].

No current data are available on healthcare professionals' awareness and perception of ICU ambient sounds. Studies investigating possible effects of ICU noise in an experimental setting are wanted. The aim of this study was to assess possible well-being and health-related factors that might be affected by ICU noise. To this end, an online survey as well as an experiment was conducted.

\section{Methods}

The aim of the online survey was to assess whether healthcare professionals in German-speaking Switzerland are aware of increased sound levels on ICUs and whether they perceive noise as a strain-inducing factor. Further, different noise sources in ICUs (such as different alarms and equipment sounds) were examined according to perceived irritation and sound levels.

The aim of the noise exposure experiment was to evaluate potential effects of ICUnoise exposure on cognitive performance and on different self-rated variables including stress, distraction, performance, or annoyance.

\section{Design and materials}

For the online survey, a 17-item questionnaire was used based on a previously developed questionnaire by Ryherd, Waye, and Ljungkvist [13]: The items were translated to German and formulated as questions. Further, some of the items were left out, others were added (see Fig. 2). Questions were answered on a four-point Likert scale (1 = "no"; 2 = "rather no"; 3 = "rather yes", 4 = "yes"). Additionally, 20 ICU-noise sources were listed (see Table 1 for noise sources). Each source was rated according to its 
Table 1 Irritation ratings and sound level estimations of 20 noise sources per category

\begin{tabular}{|c|c|c|c|c|c|}
\hline \multirow[b]{2}{*}{ Noise source } & \multicolumn{2}{|c|}{ Irritation rating } & \multicolumn{2}{|c|}{ dBA estimation } & \multirow{2}{*}{$\begin{array}{l}\text { Sound level } \\
\text { (in } \mathrm{dBA} \text { ) }\end{array}$} \\
\hline & Mean \pm SD & Rank & Mean \pm SD & Rank & \\
\hline Telephone & $3.26 \pm 0.81$ & 1 & $63.4 \pm 13.7$ & 3 & $70-80[28]$ \\
\hline Surveillance monitor (alarms) & $3.21 \pm 0.72$ & 2 & $67.0 \pm 13.1$ & 2 & $44-78[29]$ \\
\hline Conversation of colleagues & $3.10 \pm 0.82$ & 3 & $63.3 \pm 14.6$ & 4 & $59-90[29]$ \\
\hline Open packages & $3.08 \pm 1.01$ & 4 & $68.4 \pm 19.2$ & 1 & 86 [29] \\
\hline Pager & $2.92 \pm 0.98$ & 5 & $58.9 \pm 18.7$ & 9 & $84[28]$ \\
\hline Dialysis machine & $2.75 \pm 0.89$ & 6 & $60.3 \pm 18.8$ & 7 & $55[\mathrm{a}]$ \\
\hline Mechanical ventilators & $2.74 \pm 0.83$ & 7 & $60.7 \pm 15.8$ & 6 & $49-77[7]$ \\
\hline Squeaking shoes & $2.68 \pm 0.97$ & 8 & $52.4 \pm 18.8$ & 17 & \\
\hline Medical visit & $2.58 \pm 0.92$ & 9 & $59.8 \pm 15.4$ & 8 & $59-90[29]$ \\
\hline Syringe pump & $2.57 \pm 0.85$ & 10 & $55.1 \pm 19.4$ & 14 & \\
\hline Suction pump & $2.47 \pm 0.89$ & 11 & $55.6 \pm 16.5$ & 11 & 70-82 [7] (open) \\
\hline Transport monitor, ventilator & $2.41 \pm 0.82$ & 12 & $60.7 \pm 16.6$ & 5 & \\
\hline Ringing/bell & $2.39 \pm 0.94$ & 13 & $55.2 \pm 18.2$ & 12 & $40[\mathrm{a}]$ \\
\hline ECMO machine & $2.36 \pm 1.02$ & 14 & $56.4 \pm 20.3$ & 10 & \\
\hline Open/close drawers & $2.30 \pm 0.88$ & 15 & $52.7 \pm 19.1$ & 16 & $85.7[7]$ \\
\hline Conversation of visitors & $2.29 \pm 0.76$ & 16 & $53.8 \pm 15.2$ & 15 & $59-90[29]$ \\
\hline Brake on the bed & $2.18 \pm 0.98$ & 17 & $55.1 \pm 21.2$ & 13 & \\
\hline Heated blanket & $2.16 \pm 0.92$ & 18 & $44.0 \pm 18.9$ & 19 & $40[\mathrm{a}]$ \\
\hline Compressed air & $2.10 \pm 0.93$ & 19 & $51.7 \pm 20.4$ & 18 & 70-77 [7] (open) \\
\hline Thoracic drainage & $1.60 \pm 0.69$ & 20 & $36.2 \pm 19.2$ & 20 & 45 [a] \\
\hline
\end{tabular}

$d B A$ A-weighted decibel scale, ECMO extracorporeal membrane oxygenation

Sources: [a] measurements by authors of this study [7]; Tsiou, Eftymiatos, Theodossopoulou, Notis, and Kiriakou, 1998 [28]; Sommargren, 1995 [29]; Pugh, 2007; blanks: no measures available

perceived irritation on a 4-point scale (from $1=$ "not at all irritating" to $4=$ "very irritating"). An estimation of $\mathrm{dBA}$ level was requested with provision of five reference values (" $0 \mathrm{dBA}$ : hearing threshold; $25 \mathrm{dBA}$ : breathing sound; $50 \mathrm{dBA}$ : bird twittering; 75 dBA: car; 100 dBA: circular saw").

The experimental setting noise exposure was performed with the grouping variable (ICU-healthcare professional $\mathrm{HCP} /$ controls) as between-subject variation and noise condition (ICU noise/pink noise) as within-subject variation. A record of a cardiopulmonary resuscitation (CPR) simulation in an ICU environment (55-85 dBA) was chosen as the ICU-noise condition, whereas pink noise served as baseline condition (35 dBA). Pink noise is a random sound containing all frequencies but with decreasing power over the frequency spectrum. Studies suggest that pink noise-in contrast to other ambient sounds-has no negative effect on cognitive performance [21, 22]. All participants attended in two sessions (range 12 to 72 days). Half of them were tested under ICU noise in the first, and pink noise in the second session whereas the other half was exposed to the ICU noise first. Stratified randomization based on the groups to assign the timepoint of condition was used. The procedure of the experimental noise exposure is explained in Fig. 1. One session was divided into three parts, each part consisting of a rest-phase where pictures-randomly chosen out of the OASIS [23] - were shown, and of a two-back object-location working memory task (WMT). In the WMT, different digits appeared consecutively on different locations of the screen and participants had 


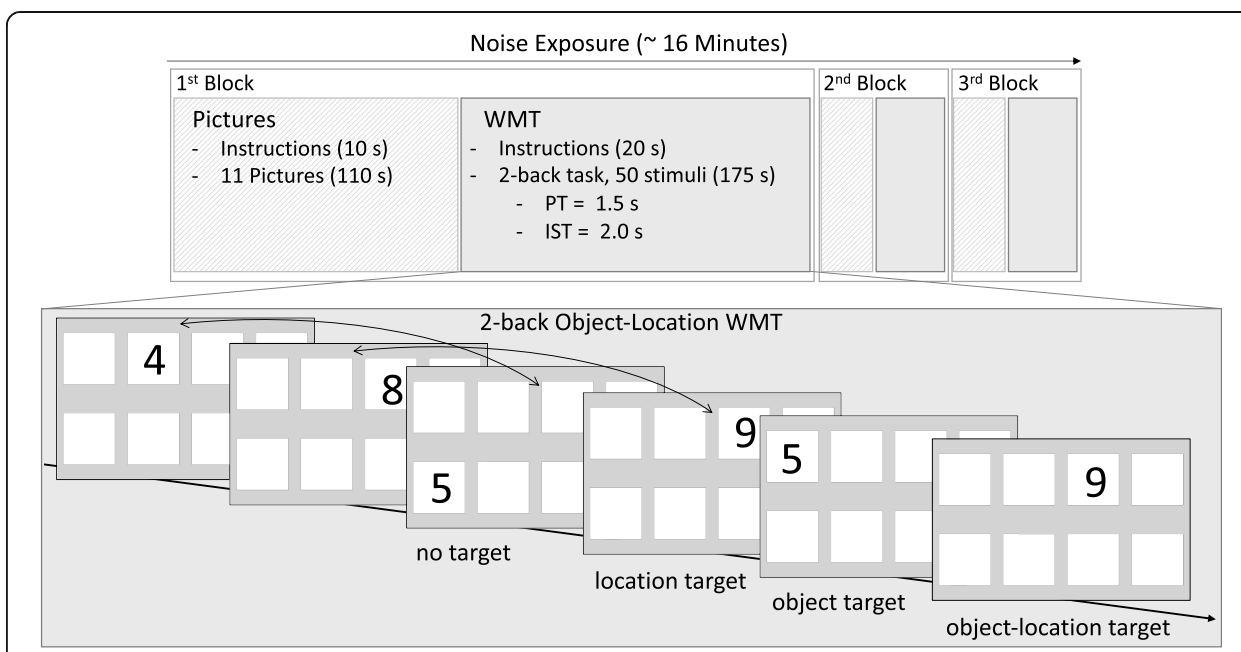

Fig. 1 Procedure of the experimental noise exposure. One session consisted of three blocks with each block being divided into a pictures-viewing part and a working memory task. Participants had to press a yes button if either the current number and/or the box was the same as two steps before (targets). If not, a no button had to be pressed. WMT, working memory task; PT, presentation time; IST, interstimulus time

to answer via a response box whether the current digit was a target (same object or same location as two steps before) or not. Overall, subjects were exposed for approximately $16 \mathrm{~min}$ to the noise.

Before and after noise exposure, questionnaires were assessed: Besides demographic information, German versions of the Weinstein Noise Sensitivity-Scale (WNS) [24, 25] and the Morningness-Eveningness-Questionnaires (D-MEQ) [26] were conducted in the beginning of the first session. Further, in both sessions, a sleep quality questionnaire (SF-A/R [27]), as well as questions on caffeine alcohol, and drug use were conducted. A visual scale was used to assess participants' selfrated stress level and one for self-rated alertness. In both sessions, the task was followed by a questionnaire including perceived stress ( 0 "not at all stressful" to 100 "very stressful"), performance, annoyance, and distraction (1 "not at all" to 4 "strongly") (see Table 3 for questions).

\section{Participants}

The web link to the questionnaire was distributed via email to different ICUs from the German-speaking part of Switzerland. Participants were motivated to distribute the link among their colleagues. The questionnaire was accessible from 12 March to 19 June 2019.

Participants for the experimental study part were recruited at the University Hospital Bern and directly contacted by email. All participants had normal or, in one case, corrected-to-normal hearing with a hearing device.

\section{Statistical analysis}

Relative proportions of the given answers of the first online survey part were evaluated. For the irritation ratings and estimations of dBA levels, descriptive statistics were used. To evaluate whether estimations of $\mathrm{dBA}$ were linked to irritation ratings, a linear 
regression model over all 20 noise sources was conducted. Other sources that were named in a free text box were gathered.

Independent-two-samples $t$-tests for difference in mean age between groups and conditions were conducted for the noise exposure experiment. Due to lack of normal distribution, strain and alertness ratings were analyzed with the non-parametric Wilcoxon ranksum test for paired measurements to check for differences between conditions. Mixed analysis of variances (ANOVAs) with noise condition as a within and group membership as a between variable were computed to analyze differences in sleep quality. A two-way between ANOVA for Weinstein noise sensitivity scores was conducted to detect possible differences between HCPs and controls as well as between noise conditions. Further, the effect of age and of the dummy-coded grouping variable (controls $=0$ ) on noise sensitivity was evaluated with a multiple linear regression model.

As outcome variables of the WMT, a performance and an accuracy measure were calculated. Performance was calculated as ratio of correct answers to all items and thus included no responses whereas accuracy refers to the specificity of a given answer by calculating the ratio of correct answers to all given answers, with no responses being ignored.

For further analysis of effects on performance and accuracy, multiple linear regressions with group, condition, and age as predictors were conducted for each timepoint.

Performance and accuracy over the separate blocks per session, was analyzed with a mixed ANOVA. Besides group and noise conditions as between variables, block number was included as a repeated within variable, condition as a between variable.

Due to lack of normal distribution paired Wilcox rank-sum tests were conducted to compare post-questions about stress-level, performance, annoyance, and distraction between the two noise conditions.

All tests of significance were conducted with the RStudio Software (Version 1.1.414) against a level of $\alpha=0.05$.

\section{Results}

\section{Online survey}

Three hundred forty-eight healthcare professionals (273 females) from the Germanspeaking part of Switzerland participated in the online survey (16 incomplete questionnaires). Mean age was $M=39.5$ years ( \pm 9.8 , range 21 to 63). Besides 200 experts in critical care, 73 participants were in training to become experts, 44 were nursing professionals, 16 were senior physicians, and 15 were assistant physicians.

Relative proportions of answers on the first 17 items of the online survey are given in Fig. 2. Mean irritation ratings and dBA estimations per noise source are indicated in Table 1. Pearson correlation between mean irritation ratings over all participants with mean dBA estimates was $r(18)=0.88, p<0.001$. Sound level estimations significantly contributed to prediction of irritation ratings $(\beta=0.05, p<0.001)$. The predictor explained $77 \%$ of the variance $\left(R^{2}=0.771, F(1,18)=60.7, p<0.01\right)$. Further irritating noise sources can be found in the supplement (Additional file 1).

\section{Experiment}

Twenty-six healthcare professionals (21 females) and 27 controls (20 females) without previous working experience in a medical setting participated in the noise exposure 


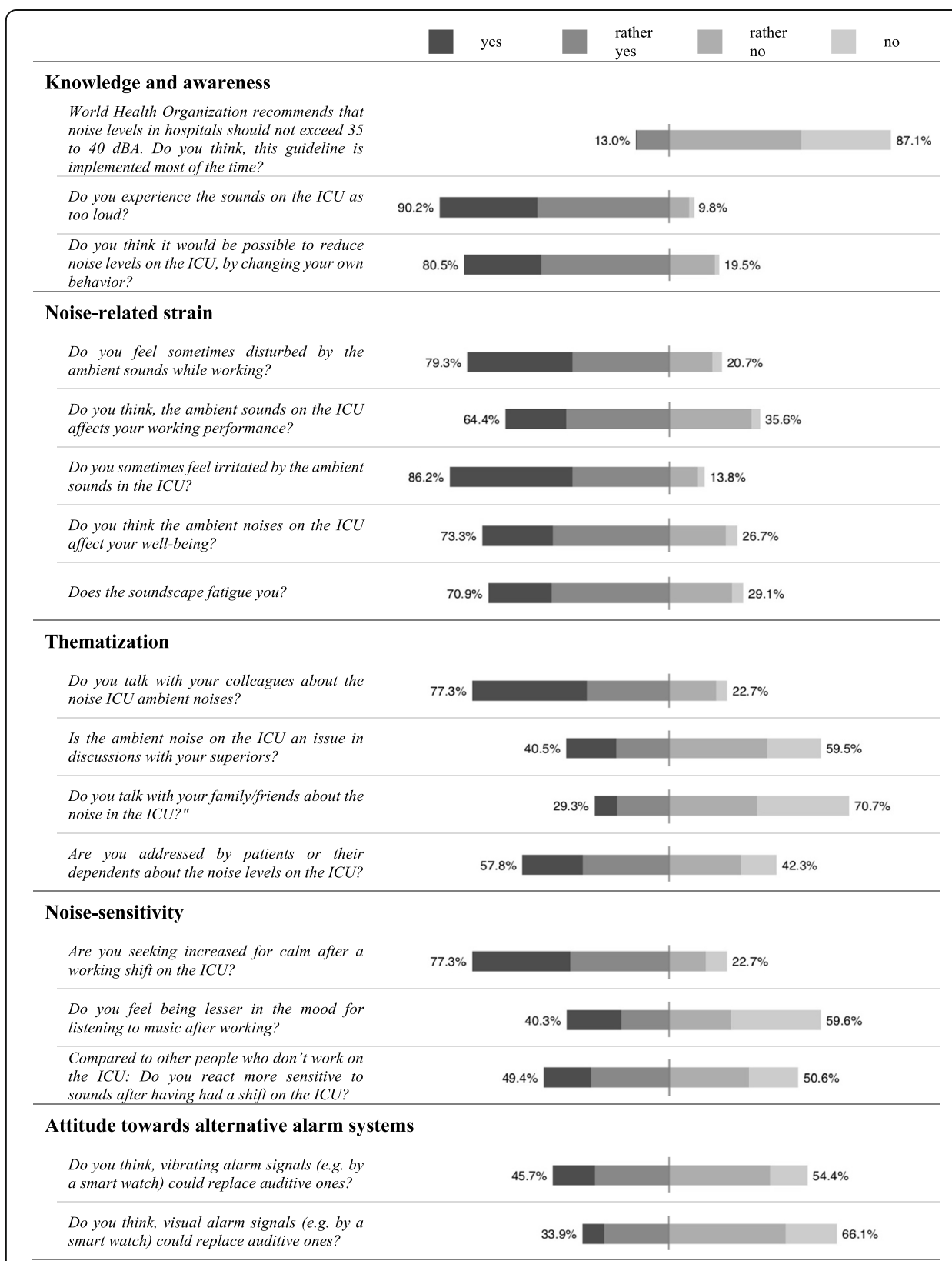

Fig. 2 Online survey results. Percentages of "yes" and "rather yes" compared to "no" and "rather no" answers

experiment. Mean age was $M=33.2( \pm 11.8$, range 19-59), whereas on mean age of healthcare professionals was higher $(M=36.7$ years, \pm 9.67$)$ than of controls $(M=29.9$ years, \pm 12.9 ).

Analysis of the pre-noise exposure questionnaire measurements did not show any significant differences between conditions or groups concerning sleep quality, strain, and alertness. Mean age of controls $(M=29.9, \pm 12.9)$ was significantly lower than mean age of the HCP group $(M=36.7, \pm 9.67), t(48.1)=2.188, p=0.03$. Noise sensitivity scores did not differ between noise conditions $(F(1,49)=1.84, p=0.18)$ but did between the two groups $(F(1,49)=11.76, p=0.001)$. With a mean score of $M=50( \pm$ 
12.2), noise sensitivity of controls was significantly lower than of HCPs (mean of $M=$ $61, \pm 10.8)$. Only the grouping variable $(\beta=10.1, p<0.01)$ not the age variable $(\beta=$ $0.13, p<0.37)$ contributed significantly to prediction of noise sensitivity in a regression model $\left(R^{2}=0.20, F(2,50)=6.23, p<0.01\right)$. When excluding controls, age as a predictor for noise sensitivity scores in HCPs reached significance $\left(\beta=0.46, p=0.04, R^{2}=\right.$ $0.17, F(1,24)=4.97, p=0.04)$. The model including the duration subjects already worked in an ICU was significant $\left(\beta=0.54, p=0.04, R^{2}=0.16, F(1,24)=4.61, p=\right.$ 0.04). Age and ICU experience strongly correlated with $r(24)=0.93, p<0.001$.

Mean 2-back task accuracy and performance per session are indicated in Table 2.

In the linear regression, age was the only significant contributing factor to variance in accuracy of the first $\left(\beta=-0.003, p<0.01, R^{2}=0.26, F(3,49)=5.85, p<0.01\right)$ and second session $\left(\beta=-0.004, p<0.01, R^{2}=0.28, F(3,49)=6.29, p<0.01\right)$ as well as to variance in performance of the first $\left(\beta=-0.008, p<0.01, R^{2}=0.46, F(3,49)=13.9, p<0.01\right)$ and second session $\left(\beta=-0.008, p<0.01, R^{2}=0.38, F(3,49)=9.88, p<0.01\right)$. Neither the effects of group nor noise condition reached significance in one of the models. Mixed ANOVAs did not show any main effect of the grouping variable, noise condition, or block. Further, none of their interactions reached significance. Detailed values can be found in the supplement (Additional file 2). The results indicate that improvements in accuracy and performance over blocks do not differ between conditions or groups.

Results of post questionnaires comparing ICU and pink noise conditions are given in Table 3.

\section{Discussion}

\section{Awareness and perceived strain}

The results of the online survey indicate that awareness of heightened sound levels is common among healthcare professionals. A majority of participants perceived the ICU as a loud environment and knew that sound levels could exceed WHO recommendations. Most participants stated that ICU ambient sounds could impair well-being and working performance, e.g., by inducing fatigue and irritation.

These findings are in line with data from Ryherd, Waye, and Ljungkvist who collected data of 47 HCPs with a similar questionnaire [13]. However, in the current survey, more participants reported to be affected by noise with a higher proportion of participants reporting having previously discussed the issue with colleagues or superiors. Thus, noise might be a matter of concern.

\section{Noise-induced annoyance}

As expected, several ICU noises are perceived as irritating and annoying. There is evidence that the degree of annoyance does not solely depend on acoustical but also on

Table 2 Working memory task performance and accuracy per noise condition and sessions. The values represented are mean \pm standard deviation

\begin{tabular}{llllll}
\hline & \multicolumn{2}{l}{ Performance } & & \multicolumn{2}{l}{ Accuracy } \\
\cline { 2 - 3 } & ICU noise & Pink noise & & ICU noise & Pink noise \\
\hline Session 1 & $0.76 \pm 0.13$ & $0.78 \pm 0.14$ & & $0.84 \pm 0.10$ & $0.84 \pm 0.08$ \\
Session 2 & $0.82 \pm 0.14$ & $0.82 \pm 0.17$ & & $0.85 \pm 0.09$ & $0.87 \pm 0.12$ \\
\hline
\end{tabular}


Table 3 Results of post-task questions about perceived strains by noise conditions

\begin{tabular}{|c|c|c|c|c|c|c|}
\hline Questions & Noise & $\begin{array}{l}\text { Mean } \pm \\
\text { SD }\end{array}$ & Median & Z & p & Sign \\
\hline \multirow[t]{2}{*}{ "How stressed did you feel during the task?" } & Pink & $\begin{array}{l}47.1 \pm \\
23.9\end{array}$ & 50 & 856.5 & 0.002 & ** \\
\hline & ICU & $\begin{array}{l}61.6 \pm \\
19.2\end{array}$ & 66.5 & & & \\
\hline \multirow[t]{2}{*}{ "I experienced the background sound as too loud." } & Pink & $\begin{array}{l}1.96 \pm \\
0.71\end{array}$ & 2 & 762 & $<0.001$ & $* * *$ \\
\hline & ICU & $\begin{array}{l}2.87 \pm \\
0.89\end{array}$ & 3 & & & \\
\hline \multirow[t]{2}{*}{$\begin{array}{l}\text { "During the n-Back task, I felt distracted by the background } \\
\text { sound." }\end{array}$} & Pink & $\begin{array}{l}1.96 \pm \\
0.79\end{array}$ & 2 & 640 & $<0.001$ & $* * *$ \\
\hline & ICU & $\begin{array}{l}2.87 \pm \\
0.95\end{array}$ & 3 & & & \\
\hline \multirow[t]{2}{*}{ "I felt annoyed by the background sounds." } & Pink & $\begin{array}{l}1.83 \pm \\
0.76\end{array}$ & 2 & 355 & 0.002 & ** \\
\hline & ICU & $\begin{array}{l}2.37 \pm \\
0.91\end{array}$ & 2 & & & \\
\hline \multirow[t]{2}{*}{ "I was able to solve the task reliable and correctly." } & Pink & $\begin{array}{l}2.38 \pm \\
0.77\end{array}$ & 3 & 107 & 0.007 & ** \\
\hline & ICU & $\begin{array}{l}2.00 \pm \\
0.77\end{array}$ & 2 & & & \\
\hline
\end{tabular}

$S D$ standard deviation, sign significance

${ }^{*} p<0.05$

${ }^{* *} p<0.01$

${ }^{* * *} p<0.001$

non-acoustical features (e.g., unpredictability, timing) [2, 30]. Especially sudden and loud alarming signals and staff-generated noises seem to be the most annoying for patients [6] and for healthcare professionals [9, 31].

\section{Noise and stress}

In the described experimental setting, self-rated stress levels were significantly higher after ICU noise versus pink noise exposure, indicating that healthcare professionals may perceive ICU-noises as stressful. These results are in line with other studies, which used self-ratings or physiological measures as stress indicators $[9,10]$. It seems likely that sound levels might play a mediating rather than a causal role: better coping with stress may theoretically occur when noise levels are low [32]. Since long term effects of stress are highly relevant for physiological and mental health [1], physiological stress answers (e.g., measurements of skin conductance or heart rate variability) in $\mathrm{HCPs}$ should be examined and might be considered outcome factors in subsequent noise intervention studies.

\section{Cognitive and task performance}

Ambient sounds in an ICU meet most criteria that are known to disturb working memory performance: They are discontinuous, have changing states, and often contain speech [19]-even though the results of the 2-back WMT did not show any significant changes of performance. This seems to contradict the results of Murthy et al. who assessed the effect of operating room soundscape on the cognitive efficiency of anesthetist [16]. Several factors might have led to this discrepancy: First, Murthy and 
colleagues did not use the same cognitive tests. Possibly, the 2-back task used in this study might be less sensitive to detect differences between respective conditions. Second, participants' mean age and variation of age were lower in the study of Murthy et al. and thus, working memory performance might have varied to a smaller degree between subjects. Third, in Murthy and colleagues' study, noise exposure was longer. Fourth, pink noise at a level of $35 \mathrm{dBA}$ was used as a control background sound, whereas Murthy and colleagues conducted a silent control condition.

In addition, several studies that looked at job-specific task performance rather than at mental efficiency failed to show significant effects [33, 34]. Possibly, healthcare professionals adapted to noisy working conditions or ambient sounds on ICUs, hence their performance is simply not affected.

But even though clear evidence is missing, there are at least three reasons that may justify the assumption that noise exposure could impair performance: First, self-ratings of this and other studies indicate that a majority of ICU healthcare professionals perceive ambient noise as performance reducing $[13,14]$. Second, annoyance is often a consequence of increased mental workload due to distractions and thereby a sign of reduced cognitive resources [19]. From this viewpoint, noise-induced annoyance could be linked to diminished working performance. Third, noise is a stressor and thus, over time, might reduce cognitive resources [35].

Again, the influence of noise on working memory and task performance might depend on the specific task and person [36]. Further, possible effects might be delayed: e.g., increased coping efforts during work could lead to diminished cognitive capacity and increased fatigue after work [37].

\section{Noise sensitivity}

HCPs participating in the experimental noise exposure had significantly higher noise sensitivity scores than controls. Even though scores did not correlate with age in controls there was a correlation in HCPs. Since noise sensitivity correlated also with the duration subjects already have been working in an ICU, it can be assumed that duration might be a mediating factor between age and sensitivity scores. This would imply that the longer someone worked on an ICU, the more sensitive they react to noises. Noiseinduced stress could accumulate over the years resulting in heightened sensitivity. Considering that at the same time lower noise sensitivity seems to improve the capacity to cope with noise-induced stress [36], noise reduction in ICUs could improve the mental and physical health of HCPs.

\section{Hospital politics}

Though most online survey participants perceived ICU noises as burden and reported to discuss the concern with colleagues, only a minority reported that the topic was addressed with superiors (e.g., with hospital management). This discrepancy seems surprising. Hospital management might develop strategies to reduce noise: studies showed significant reductions in noise levels by floor planning, alternative equipment, and materials (e.g., sound absorbing materials) $[38,39]$ or by routine changes (e.g., quiet hours) and behavioral interventions [40-44]. Behavioral interventions and exchange of information should not only address health but also cleaning staff [45]. Though our survey 
shows that skepticism concerning alternative alarming systems might be common, new and more intelligent, self-prioritizing alarming systems which are removed from the patient bed with direct reporting to staff might be helpful in the future.

\section{Limitations}

Our study has several important limitations that deserve discussion. First, generalization of the results might be challenged since some of the used questionnaires were not validated and results could be biased due to self-selection. Possibly, subjects were more willing to participate if they perceive noise as problematic. Further, all limitations of self-reporting or self-assessment (regarding the questionnaire) apply and the number of participants in the experimental setting is rather small. Second, sound pressure levels may vary strongly among ICUs and used equipment. Thus, the concern might not affect all healthcare professionals equally. Third, it is known that specific noise characteristics (e.g. volume level, pitch) have different effects on performance and well-being. In this study, a noise scenario including a wide range of sounds was used. Clearly, ambient noises (and therefore the specific noise characteristics) can vary strongly. Therefore, our results are not directly transferable to other ICU scenarios. Moreover, pink noise was used as a control condition because this is more realistic to achieve in an ICU setting than total silence. But in future work, it would be interesting to conduct a study with a third "silent control" condition. Fourth, our study-and many others in this field-used task-independent noise exposure, and thus, subjects could simply try to ignore the ambient sounds. Since in daily routine, HCPs have to pay attention to their surroundings, this approach suffers from reduced ecological validity and makes transfer of results difficult.

\section{Conclusion}

Subjective assessments indicate that noise in ICUs may induce annoyance, with heightened stress levels, impaired well-being, and reduced performance being potential consequences. Even though this and other studies did not find significant effects of ICU noise exposure on cognition. Empirical evidence with objective and physiological measures is warranted.

\section{Supplementary information}

Supplementary information accompanies this paper at https://doi.org/10.1186/s40635-020-00321-3.

Additional File 1. Further noise sources according to their categories.

Additional File 2. Results from the mixed ANOVAs of working memory performance and accuracy over three blocks separated per session.

\footnotetext{
Abbreviations

ANOVA: Analysis of variance; CPR: Cardiopulmonary resuscitation; D-MEQ: Deutscher Morningness-EveningnessQuestionnaire; ECMO: Extracorporeal membrane oxygenation; HCP: Healthcare Professionals; ICU: Intensive Care Unit; OR: Operating room; SF-A/R: Schlaffragebogen A; WHO: World Health Organization; WMT: Working memory task; WNS: Weinstein Noise Sensitivity Scale
} 


\section{Authors' contributions}

All authors contributed to the design of the study. Preparation of recordings of the ICU simulation was mainly done by BZ, SG, and MMJ, noise measures by SG, and MMJ. Programming of the experiment was done by AC. Preparation of hearing test and noise exposure devices were done by TG. Data collection was done by NS, SG, and MMJ. Data analysis was performed by NS. The manuscript was drafted by NS with all authors revising it for intellectual content. All authors contributed to the final version. All authors read and approved the final manuscript.

\section{Funding}

Funding for the study and article processing was provided by the University of Bern.

\section{Availability of data and materials}

The dataset used and analyzed during the current study are available from the corresponding author on reasonable request.

\section{Ethics approval and consent to participate}

The study was carried out in accordance with the latest version of the Declaration of Helsinki and approved by the Ethics Commission of the Faculty of Human Science, University of Bern.

All participants were informed in written form about the topic and procedure of the study. Participants in the exposure agreed to participate by signing an informed consent, the online survey participants by clicking on the "start" button. Exclusion criteria were current psychiatric or neurological disorders, and a neurotropic medication.

\section{Consent for publication}

Not applicable.

\section{Competing interests}

BZ, MMJ, and JCS (full disclosure) report grants from Orion Pharma, Abbott Nutrition International, B. Braun Medical AG, CSEM AG, Edwards Lifesciences Services GmbH, Kenta Biotech Ltd, Maquet Critical Care AB, Omnicare Clinical Research AG, Nestle, Pierre Fabre Pharma AG, Pfizer, Bard Medica S.A., Abbott AG, Anandic Medical Systems, Pan Gas AG Healthcare, Bracco, Hamilton Medical AG, Fresenius Kabi, Getinge Group Maquet AG, Dräger AG, Teleflex Medical GmbH, Glaxo Smith Kline, Merck Sharp and Dohme AG, Eli Lilly and Company, Baxter, Astellas, Astra Zeneca, CSL Behring, Novartis, Covidien, and Nycomed outside the submitted work. The money was paid into departmental funds. No personal financial gain applied. All other authors declare no conflict of interest.

\section{Author details}

${ }^{1}$ Gerontechnology \& Rehabilitation Group, University of Bern, Murtenstrasse 50, CH-3008 Bern, Switzerland.

${ }^{2}$ Department of Intensive Care Medicine, University Hospital Bern (Inselspital), University of Bern, CH-3010 Bern, Switzerland. ${ }^{3}$ Hearing Research Laboratory, University of Bern, Murtenstrasse 50, CH-3008 Bern, Switzerland. ${ }^{4}$ Department of Neurology, University Neurorehabilitation, University Hospital Bern (Inselspital), University of Bern, Freiburgstrasse, CH-3010 Bern, Switzerland. ${ }^{5}$ ARTORG Center for Biomedical Engineering Research, University of Bern, Murtenstrasse 50, CH-3008 Bern, Switzerland.

Received: 11 January 2020 Accepted: 3 July 2020

Published online: 23 July 2020

\section{References}

1. Berglund B, Lindvall T, Schwela D, World Health Organization. Occupational and Environmental Health Team (1999) Guidelines for community noise. World Health Organization

2. Passchier-Vermeer W, Passchier WF (2000) Noise exposure and public health. Environ Health Persp 108:123 https://doi. org/10.2307/3454637

3. Freedman NS, Kotzer N, Schwab RJ (1998) Patient perception of sleep quality and etiology of sleep disruption in the intensive care unit. Am J Respir Crit Care Med 159:1155-1162

4. Tainter CR, Levine AR, Quraishi SA et al (2016) Noise levels in surgical ICUs are consistently above recommended standards. Crit Care Med 44:147-152 https://doi.org/10.1097/CCM.0000000000001378

5. Darbyshire JL, Young JD (2013) An investigation of sound levels on intensive care units with reference to the WHO guidelines. Crit Care 17:R187 https://doi.org/10.1186/cc12870

6. Akansel N, Kaymakçi Ş (2008) Effects of intensive care unit noise on patients: a study on coronary artery bypass graft surgery patients. J Clin Nurs 17:1581-1590 https://doi.org/10.1111/j.1365-2702.2007.02144.X

7. Tsiou C, Eftymiatos D, Theodossopoulou E et al (1998) Noise sources and levels in the evgenidion hospital intensive care unit. Intensive Care Med 24:845-847 https://doi.org/10.1007/s001340050676

8. Delaney $\amalg$, Currie MJ, Huang $\mathrm{H}-\mathrm{CC}$ et al (2017) The nocturnal acoustical intensity of the intensive care environment: an observational study. J Intensive Care 5 https://doi.org/10.1186/s40560-017-0237-9

9. Morrison WE, Haas EC, Shaffner DH, et al (2003) Noise, stress, and annoyance in a pediatric intensive care unit: Crit Care Med 31:113-119. https://doi.org/10.1097/00003246-200301000-00018

10. Watson J, Kinstler A, Vidonish WP et al (2015) Impact of noise on nurses in pediatric intensive care units. Am J Crit Care 24:377-384 https://doi.org/10.4037/ajcc2015260

11. Topf M, Dillon E (1988) Noise-induced stress as a predictor of burnout in critical care nurses. Heart Lung 17:567-574

12. Kinzl J, Traweger C, Biebl W, Lederer W (2006) Burnout und Belastungsstörungen bei Intensivmedizinern. DMW Deutsche Medizinische Wochenschrift 131:2461-2464 https://doi.org/10.1055/s-2006-955030

13. Ryherd EE, Waye KP, Ljungkvist $L$ (2008) Characterizing noise and perceived work environment in a neurological intensive care unit. J Acoust Soc Am 123:747-756 https://doi.org/10.1121/1.2822661 
14. Gurses AP, Carayon P (2007) Performance obstacles of intensive care nurses. Nurs Res 56:185-194 https://doi.org/10. 1097/01.NNR.0000270028.75112.00

15. Padmakumar AD, Cohen O, Churton A et al (2017) Effect of noise on tasks in operating theatres: a survey of the perceptions of healthcare staff. Br J Oral Maxillofac Surg 55:164-167 https://doi.org/10.1016/j.bjoms.2016.10.011

16. Murthy VSSN, Malhotra SK, Bala I, Raghunathan M (1995) Detrimental effects of noise on anaesthetists. Can J Anaesth 42:608-611

17. Sim CS, Sung JH, Cheon SH, Lee JM, Lee JW, Lee J (2015) The effects of different noise types on heart rate variability in men. Yonsei Medical Journal 56(1):235 https://doi.org/10.3349/ymj.2015.56.1.235

18. Umemura M, Honda K, Kikucji Y (1992) Influence of noise on heart rate and quantity of work in mental work. Ann Physiol Anthropol. 11(5):523-532

19. Szalma JL, Hancock PA (2011) Noise effects on human performance: a meta-analytic synthesis. Psychol Bull 137:682-707 https://doi.org/10.1037/a0023987

20. Ellermeier W, Zimmer K (2014) The psychoacoustics of the irrelevant sound effect. Acoust. Sci. \& Tech. 35:10-16

21. Wasserman CS, Segool N (2013) Working in and with noise: the impact of audio environment on attention. Journal of Neurotherapy 17:203-212. https://doi.org/10.1080/10874208.2013.847147

22. Chitwood MR, Vaughn KE (2018) Cognitive performance and sounds: the effects of lyrical music and pink noise on performance. NKU J Stud Res 1:10-14

23. Kurdi B, Lozano S, Banaji MR (2017) Introducing the open affective standardized image set (OASIS). Behav Res Methods 49:457-470 https://doi.org/10.3758/s13428-016-0715-3

24. Weinstein ND (1978) Individual differences in reactions to noise: a longitudinal study in a college dormitory. J Appl Psychol 63:458-466 https://doi.org/10.1037/0021-9010.63.4.458

25. Zimmer K, Ellermeier W (1997) A German version of Weinstein's noise sensitivity scale. Z Lärmbekämpfung 44:107-110

26. Griefahn B, Künemund C, Bröde P, Mehnert P (2001) Zur Validität der deutschen Übersetzung des MorningnessEveningness-Questionnaires von Horne und Östberg. Somnologie 5:71-80

27. Görtelmeyer R (2011) SF-A/R und SF-B/R Schlaffragebogen A und B

28. Sommargren CE (1995) Environmental hazards in the technological age. Crit Care Nurs Clin North Am 7:287-295. https://doi.org/10.1016/S0899-5885(18)30402-7

29. Pugh RK (2007) The impact of noise in the intensive care unit. Crit Emerg Care:942-943

30. Kjellberg A, Landström U, Tesarz M et al (1996) The effects of nonphysical noise characteristics, ongoing task and noise sensitivity on annoyance and distraction due to noise at work. J Environ Psychol 16:123-136 https://doi.org/10.1006/ jevp.1996.0010

31. Park M, Kohlrausch AG, Bruijn WP, et al (2013) Source-specific analysis of the noise in an intensive care unit. Proceedings of the 42nd International Congress and Exposition on Noise Control Engineering 1-9

32. Leather P, Beale D, Sullivan L (2003) Noise, psychosocial stress and their interaction in the workplace. J Environ Psychol 23:213-222

33. Ryherd EE, Okcu S, Ackerman J et al (2012) Noise pollution in hospitals: impacts on staff. J Clin Outcomes Manag 19: $491-500$

34. Moorthy K, Munz Y, Undre S, Darzi A (2004) Objective evaluation of the effect of noise on the performance of a complex laparoscopic task. Surgery 136:25-30

35. Sandi C (2013) Stress and cognition: Stress and cognition. Wiley Interdisciplinary Reviews: Cogn Sci 4:245-261 https:// doi.org/10.1002/wcs.1222

36. Topf M (1989) Sensitivity to noise, personality, hardiness, and noise-induced stress in critical care nurses. Environ Behav 21:717-733

37. Kjellberg A, Muhr P, Skoldstrom B (1998) Fatigue after work in noise - an epidemiological survey study and three quas experimental field study. Noise Health 1:47-55

38. Blomkvist V (2005) Acoustics and psychosocial environment in intensive coronary care. Occup Environ Med 62:e1-e1 https://doi.org/10.1136/oem.2004.017632

39. Petterson M (2000) Reduced noise levels in ICU promote rest and healing. Crit Care Nurse 20:104

40. McAndrew NS, Leske J, Guttormson J et al (2016) Quiet time for mechanically ventilated patients in the medical intensive care unit. Intensive Crit Care Nurs 35:22-27 https://doi.org/10.1016/j.iccn.2016.01.003

41. Richardson A, Thompson A, Coghill E, et al (2009) Development and implementation of a noise reduction intervention programme: a pre- and postaudit of three hospital wards. J Clin Nurs 18:3316-3324. https://doi.org/10.1111/j.1365-2702. 2009.02897.x

42. Kahn DM, Cook TE, Carlisle CC et al (1998) Identification and modification of environmental noise in an ICU setting. Chest 114:535-540 https://doi.org/10.1378/chest.114.2.535

43. Swathi S, Ramesh A, Nagapoornima M et al (2014) Sustaining a "culture of silence" in the neonatal intensive care unit during nonemergency situations: a grounded theory on ensuring adherence to behavioral modification to reduce noise levels. Int J Qual Stud Health Well-being 9:22523 https://doi.org/10.3402/qhw.v9.22523

44. Monsén MG, Edéll-Gustafsson UM (2005) Noise and sleep disturbance factors before and after implementation of a behavioural modification programme. Intensive Crit Care Nurs 21:208-219 https://doi.org/10.1016/j.iccn.2004.12.002

45. Sasso L, Bagnasco A, Aleo G et al (2016) Editorial: noise on hospital wards - what have we learned? J Clin Nurs 25:891893 https://doi.org/10.1111/jocn.13200

\section{Publisher's Note}

Springer Nature remains neutral with regard to jurisdictional claims in published maps and institutional affiliations. 